\title{
Role of Flag Leaf and Spike Emergence Stage on the Incidence of Karnal Bunt in Wheat
}

\author{
J. Kumar and S. Nagarajan, Directorate of Wheat Research, Karnal, Post Box 158, Haryana-132001, India
}

\begin{abstract}
Kumar, J., and Nagarajan, S. 1998. Role of flag leaf and spike emergence stage on the incidence of Karnal bunt in wheat. Plant Dis. 82:1368-1370.

Removal of the flag leaf of wheat, earlier hypothesized to act as a site where secondary sporidia of Tilletia indica multiply and conjugate, reduced the severity of Karnal bunt. Evidence reported here suggests that sporidia reach the flag leaf from the soil by splashing, multiply on the surface of the flag leaf, and move with rain water or dew into the boot of the flag leaf to cause infection of the spikelets. Plants in growth stage 49 (first awns visible) were more vulnerable to infection by secondary sporidia than were plants at other growth stages. At growth stage 49, the flag leaf lamina was fully opened, compared with its preceding stages, which had tubular and closed lamina. Also, leaf posture of the flag leaf at growth stage 49 is erect and thus may facilitate movement of sporidial inoculum into the boot. Upon completion of stage 49 , the flag leaf becomes droopy, leading to lesser inoculum movement into the emerging spike. Thus, maximum success can be achieved in artificial creation of Karnal bunt by inoculating with secondary sporidia before onset of growth stage 49. Genotypes whose maturity avoids coincidence of this critical stage of spike emergence with periods of weather favorable for infection by $T$. indica may be selected for resistance breeding.
\end{abstract}

Additional keywords: allantoid sporidia, Neovossia indica

Karnal bunt (KB) of wheat is caused by soil- and seed-borne inoculum of Tilletia indica Mitra (4,5). Recently, Nagarajan and associates reviewed the information related to the pathogen and the disease (7). During harvesting and threshing, $T$. indicainfected grains release teliospores that contaminate both the seed and soil. The soil-borne teliospores germinate during the next crop cycle and produce primary sporidia (macrosporidia) measuring 64.4 to $78.8 \mu \mathrm{m} \times 1.6$ to $1.8 \mu \mathrm{m}$, which in turn germinate to produce large amounts of crescent-shaped secondary (allantoid) sporidia measuring 11.9 to $13.0 \mu \mathrm{m} \times 2.0$ to $2.03 \mu \mathrm{m}$. The primary sporidia move from the surface soil to lower leaves by wind and rain splashing. On wet leaf surfaces, secondary sporidia are produced in copious amounts $(8,9)$. These spores then travel upward and reach the flag leaf by splashing (6). The hypothesis is that secondary sporidia propagate on the flag leaf, and being heterothallic (3), conjugate at some point prior to infecting spikelets. A mild drizzle or rain at this stage washes the sporidia down into the flag leaf sheath, where they infect the emerging spikelets. Genotypes characterized by growth cycles

Corresponding author: S. Nagarajan

E mail: dowr@x400.nicgw.nic.in

Accepted for publication 27 August 1998.

Publication no. D-1998-1022-01R

(C) 1998 The American Phytopathological Society that escape favorable periods of weather for $\mathrm{KB}$ infection can be selected as resistant stocks.

In this report, we present evidence that supports the hypothesis that the flag leaf acts as a site for propagation of secondary sporidia, thus promoting KB infection (6). To facilitate the development of heavy disease pressure on the materials to be selected for $\mathrm{KB}$ resistance, the growth stages favoring maximum development of disease were identified. These stages are most favorable for artificial inoculation of test materials (1).

\section{MATERIALS AND METHODS}

Experiments were conducted during the cropping season of 1995-96 and repeated in 1996-97 at Dhaulakuon, Himachal Pradesh, India, located at the foothills of the Himalayan Mountains, in which KB is endemic. Ideal weather conditions for $\mathrm{KB}$ development, namely rain or drizzle, cloudy weather, high humidity (>70\% relative humidity), and conducive temperatures $\left(12\right.$ to $20^{\circ} \mathrm{C}$ ), prevail here between 15 January and the end of February (Table 1). During this period, the wheat cultivars, whether late maturing (sown on 15 November) or early maturing (sown on 15 December), arrive at spike emergence stages that are vulnerable to infection. Development and severity of KB was examined on the six spring wheat cultivars HD2009, WL711, Sonalika, HD2329, HD2285, and WH147. These six genotypes were chosen because they are highly susceptible to KB under field conditions (10).

Role of flag leaf in disease cycle of KB. The trials were laid out using appropriate split-plot design, with cultivars being main treatment and flag leaf the subtreatment. Cultivars were planted by drilling their seeds into separate rows with 4-m length and 23-cm spacing. Rows of each cultivar were replicated three times. Each cultivar was sown on two dates to provide a better chance that spike emergence would coincide with favorable weather for KB. Late-maturing (approximately 140 days) cultivars WL711, HD2009, HD2329, and WH147 were sown on 15 November, and early-maturing (approximately 105 days) cultivars Sonalika and HD2285 were sown on 15 December. Fertilizers were applied with $60 \mathrm{~kg} \mathrm{~N}, 30 \mathrm{~kg}$ P, and $20 \mathrm{~kg} \mathrm{~K}$ per hectare. Rows were topdressed individually with a second dose of $\mathrm{N}$ (60 kg/ha or $11 \mathrm{~g}$ per $4-\mathrm{m}$ row) before irrigation at the crown root initiation stage. Hand irrigation was provided in rows when cultivars attained crown root initiation, tiller completion, boot, and milk stages of growth. Rows were kept free of weeds by manual operations only.

In each row, three random spikes on the tillers that had attained growth stage 39 (11) were paired. Spikes were paired by tying two tillers of the same maturity together with a cotton thread at the base of the spikes. The flag leaf of one plant in each pair was clipped at the auricle level, while that of the other was retained to serve as the control. After harvest, the spikes of each pair were threshed separately, and the severity of $\mathrm{KB}$ in each one was measured as percent infected grains. Averages of infected grains of three spikes

Table 1. Weather regime of Dhaulakuon during spike emergence from 15 January to 28 February (44 days) in 1995 and 1996

\begin{tabular}{|c|c|c|c|c|c|}
\hline \multirow[b]{2}{*}{ Year } & \multicolumn{2}{|c|}{ Daily temperature $\left({ }^{\circ} \mathbf{C}\right)$} & \multicolumn{2}{|c|}{ Daily relative humidity $(\%)$} & \multirow{2}{*}{$\begin{array}{c}\text { Foggy days } \\
\text { with dew (no.) }\end{array}$} \\
\hline & Range & Mean & Range & Mean & \\
\hline 1995 & $2-19$ & 11 & $62-91$ & 76 & $26^{a} / 44$ \\
\hline 1996 & $3-21$ & 12 & $58-88$ & 71 & $22^{\mathrm{a}} / 44$ \\
\hline
\end{tabular}

${ }^{a}$ Remainder of the days were either cloudy without fog or rainy. 
in each row (separately for clipped and unclipped spikes) were calculated, and the data were subjected to an arcsine transformation before analysis of variance.

Vulnerability of spike emergence stages to KB. Another experiment designed to discover the comparative vulnerability of spike emergence stages to natural infection of $\mathrm{KB}$ was examined in the same rows (described in previous experiment) of cultivars HD2009, WL711, and Sonalika.

The trials were laid out using appropriate split-plot design, with spike emergence stages as main treatments and cultivars as subtreatments. In each row, 18 culms of plants that attained growth stage 37 (flag leaf just visible) were individually enclosed in $36 \times 36 \mathrm{~cm}$ envelopes made of white, transparent glossy paper. These envelopes provided appropriate space to accommodate the spike without disturbing the natural posture of the flag leaf. Envelopes from three spikes per row were re- moved as tillers attained growth stages 41 , $43,49,52,54,56,58$, and 60 . The spikes were exposed for $48 \mathrm{~h}$ (from 9:00 A.M. of the first day to 9:00 A.M. of the third day). Following the period of exposure, each spike was covered with an envelope. Abundant deposition of dew, minimum up to 9:00 A.M., was recorded during the days of exposure of all stages in all the cultivars under study for both years. The spikes were harvested separately and threshed manually. The severity of KB was calculated by counting the percent infected grains in the harvested lots. Data were subjected to an arcsine transformation before analysis of variance.

Flag leaf morphology. The upper twothirds of the flag leaf drooped away from the main axis of its tiller at all spike emergence stages, but the lower one-third of the flag leaf had a more upright posture. Using a protractor, the flag leaf angle of the basal one-third of the flag leaf was measured at

Table 2. Impact of the presence and absence of flag leaf on incidence of Karnal bunt (KB) of spring wheat

\begin{tabular}{|c|c|c|c|c|}
\hline \multirow[b]{3}{*}{ Cultivar } & \multicolumn{4}{|c|}{ Disease incidence $^{\text {a }} \%$ infected grains per spike) } \\
\hline & \multicolumn{2}{|c|}{1995} & \multicolumn{2}{|c|}{1996} \\
\hline & No flag leaf & Flag leaf & No flag leaf & Flag leaf \\
\hline HD2009 & 2.7 & 38 & 2.0 & 33 \\
\hline WL711 & 2.0 & 36 & 2.3 & 37 \\
\hline HD2329 & 4.4 & 25 & 4.8 & 26 \\
\hline Sonalika & 3.7 & 16 & 4.2 & 15 \\
\hline HD2285 & 2.3 & 14 & 2.1 & 25 \\
\hline \multirow[t]{2}{*}{ WH147 } & 5.6 & 15 & 9.1 & 15 \\
\hline & \multicolumn{2}{|c|}{$\begin{array}{c}\operatorname{SED}^{\mathrm{b}}=1.63 \\
\mathrm{LSD}^{2} \%=5.01^{\mathrm{c}}\end{array}$} & \multicolumn{2}{|c|}{$\begin{array}{c}\text { SED }=3.55 \\
\text { LSD 5\% }=10.90^{\circ}\end{array}$} \\
\hline \multirow{2}{*}{$\begin{array}{l}\text { Overall mean } \\
\text { (All cultivars) }\end{array}$} & 3.45 & 23.92 & 4.09 & 25.31 \\
\hline & \multicolumn{2}{|c|}{$\begin{array}{c}\text { SED }=0.66 \\
\text { LSD 5\% }=2.04^{\mathrm{d}}\end{array}$} & \multicolumn{2}{|c|}{$\begin{array}{c}\text { SED }=1.44 \\
\text { LSD 5\% }=4.45^{\mathrm{d}}\end{array}$} \\
\hline
\end{tabular}

a Mean value of nine spikes from three rows.

${ }^{\mathrm{b}} \mathrm{SED}=$ standard error of difference of two means. LSD = least square difference.

${ }^{\mathrm{c}}$ For testing the significant difference of KB severity in spikes without and with flag leaf within cultivars

${ }^{\mathrm{d}}$ For testing the significant difference of overall KB severity of all cultivars without and with flag leaf. each growth stage, and the posture was designated as erect (45 to $90^{\circ}$ angle to ground axis at ligular point) or flat (below $45^{\circ}$ to ground axis at ligular point).

Laminar curvature of the flag leaf was also observed at each spike emergence stage. A flag leaf with its two margins folding inward was designated as tubular, while a leaf without any fold and having a fully extended lamina was designated as fully opened.

All spike emergence stages were observed for the presence of incisions of the boot, which developed as a result of separation of the margins of the boot leaf sheath. The incisions resulted from swelling of the spike inside the boot after completion of stage 49. However, the boot leaf sheath remained intact until completion of stage 49 for all cultivars in this study.

\section{RESULTS}

Role of flag leaf in development of KB. The overall levels of KB severity in spikes with flag leaves were significantly higher than without flag leaves (Table 2). The only exception was with cultivar WH147 in 1996.

Vulnerability of spike emergence stages to $T$. indica infection. Vulnerability to infection at various spike emergence stages under natural conditions was simultaneously examined on three cultivars highly susceptible to KB (Table 3). No KB occurred in spikes exposed at growth stage 41 , when the flag leaf sheath began extending. However, incidence was much higher when bags were removed at stage 43 , when boots were beginning to swell. The infection process halted after growth stage 58, when the inflorescence had completely emerged. Grains harvested from spikes exposed at growth stage 60 (beginning of anthesis) were free of Karnal bunt. In all cultivars, the incidence of KB was the highest in those spikes exposed at stage 49 , when awns are first visible.

Table 3. Impact of flag leaf posture, laminar curvature, and growth stages on Karnal bunt on three susceptible spring bread wheats

\begin{tabular}{|c|c|c|c|c|c|c|c|c|c|c|}
\hline \multirow{3}{*}{$\begin{array}{l}\text { Stage of } \\
\text { exposure }^{b}\end{array}$} & \multirow{2}{*}{\multicolumn{2}{|c|}{$\begin{array}{l}\text { Condition of flag leaf } \\
\text { (upper } 2 / 3 \text { droopy) }\end{array}$}} & \multicolumn{8}{|c|}{ Disease incidence (\% infected grains per spike) } \\
\hline & & & \multicolumn{3}{|c|}{1995} & \multicolumn{3}{|c|}{1996} & \multicolumn{2}{|c|}{ Yearwise mean } \\
\hline & Lower 1/3 & Curvature & WL711 & HD2009 & Sonalika & WL711 & HD2009 & Sonalika & 1995 & 1996 \\
\hline $41^{\mathrm{c}}$ & Erect & Tubular & 0 & 0 & 0 & 0 & 0 & 0 & 0 & 0 \\
\hline 43 & Erect & Tubular & 8.1 & 16.4 & 6.0 & 16.4 & 4.0 & 5.9 & 10.1 & 8.8 \\
\hline 49 & Erect & Fully opened & 28.5 & 36.8 & 24.0 & 36.8 & 29.3 & 24.1 & 27.2 & 30.1 \\
\hline 52 & Flat & Fully opened & 15.4 & 15.3 & 10.4 & 15.3 & 7.4 & 6.3 & 14.1 & 9.7 \\
\hline 54 & Flat & Fully opened & 7.8 & 5.8 & 5.7 & 5.8 & 4.4 & 5.5 & 6.6 & 5.3 \\
\hline 56 & Flat & Fully opened & 4.4 & 6.3 & 5.1 & 6.3 & 3.5 & 4.1 & 4.8 & 4.6 \\
\hline 58 & Flat & Fully opened & 2.6 & 2.9 & 4.2 & 2.9 & 4.0 & 4.4 & 3.7 & 3.8 \\
\hline $60^{c}$ & Flat & Fully opened & 0 & 0 & 0 & 0 & 0 & 0 & 0 & 0 \\
\hline SED $^{d}$ & & & & 1.64 & & & 1.39 & & & \\
\hline LSD $5 \% \mathrm{e}$ & & & & 5.28 & & & 4.47 & & & \\
\hline
\end{tabular}

a Mean value of nine spikes from three rows.

${ }^{\mathrm{b}}$ In each cultivar, 72 spikes of plants that attained growth stage 37 were covered with envelopes. Envelopes were removed at successive growth stages 41 , $43,49,52,54,56,58$, and 60 (nine spikes per stage) for $48 \mathrm{~h}$, and spikes were covered again.

${ }^{\mathrm{c}}$ Not included in statistical analysis.

d $\mathrm{SED}=$ standard error of difference of two means. LSD = least square difference.

${ }^{\mathrm{e}}$ For testing the significant differences among stages within varieties. 


\section{DISCUSSION}

In an earlier experiment (6), it was hypothesized that the flag leaf acts as the catchment area of secondary sporidia of $T$. indica. Another study indicated that sporidia can germinate and multiply on host and nonhost surfaces (2). It was also postulated (6) that sporidia propagate on the flag leaf surface and move down with rain water or coalescent dew droplets into the flag leaf sheath to cause infection of spikelets of the emerging spikes. As a part of the present study, the role of the flag leaf was examined by comparing the development of $\mathrm{KB}$ severity in its presence and absence. Significantly higher levels of severity developed in those treatments that had a flag leaf compared with those without a flag leaf (Table 2).

This finding suggests a role of the flag leaf in the development of $\mathrm{KB}$ in nature and, in contrast to an earlier finding (4), suggests that the secondary sporidia do not lodge directly on the floral structures to cause infection. A modification in the disease cycle of KB can thus be hypothesized. In this model, the secondary sporidia first lodge on the flag leaf, propagate there, and then move down in water to the boot leaf sheath to cause infection of the spikelets. During this process, fusion between heterothallic secondary sporidia occur, resulting in infective propagules, since only after fusion do the sporidia cause infection (3).

The comparative susceptibility of growth stages between extension of the flag leaf sheath (growth stage 41) and the beginning of anthesis (growth stage 60) identified the critical stage of crop growth period highly prone to $\mathrm{KB}$ infection. The spikes at each growth stage were kept open for $48 \mathrm{~h}$ to coincide with the approximate length of each stage. It also ensured that spikes received natural inoculum only at a specific growth stage. The data on three susceptible genotypes indicated that maximum infection occurs at growth stage 49 (Table 3). These observations support earlier findings (1) where stage 49 was demonstrated to be the most vulnerable to $\mathrm{KB}$ when inoculum was artificially applied in a spray. This information may assist in selection of genotypes whose most vulner- able stage of growth escapes coincidence with weather favoring $\mathrm{KB}$ infection in a given area.

The buildup of KB severity in the spikes exposed at various growth stages seems dependent upon the erectness of the flag leaf at a given stage of spike emergence. As shown in Table 3, the postures of the lower one-third of the flag leaves differ at different growth stages. The laminar curvature of the flag leaf was also found to vary at different stages. According to a hypothesis (6), the flag leaf surface acts as the catchment area for the allantoid sporidia. The catch of allantoid sporidia is expected more on the surface of a flag leaf that is fully opened than on a leaf still in a tubular form. The hypothesis further says that after the sporidia are settled on the flag leaf surface, they move down with rain water or dew into the spike. The angle of flag leaf may play an important role in this process of sporidial movement. It is expected that movement is facilitated when the lower one-third of the flag leaf is erect or nearly erect (45 to $90^{\circ}$ angle to the ground axis). Lesser rundown may occur when the lower one-third of the flag leaf has drooped (flat posture, almost parallel to ground axis) after loss of erect posture.

Our experimental data support the hypothesis that stage 49 is the most vulnerable phase for infection by KB because the leaf lamina is fully opened and efficient for collecting inoculum and that the posture of the lower one-third of the flag leaf is erect, which facilitates the movement of sporidial inoculum into the spike. In all other stages, either of these two favorable morphological features is lacking; hence, incidence of $\mathrm{KB}$ was significantly less than with exposure to the pathogen at growth stage 49. At growth stage 43 , the lamina of the flag leaf does not open fully, and its curvature presumably hinders the process of sporidial settling on the laminar surface. On the other hand, the lower incidence of $\mathrm{KB}$ at the stages after 49 may be attributed to the lack of sporidial movement on a flat-postured flag leaf and the formation of an incision on the surface of boot. This incision does not permit high moisture (an essential prerequisite for establishment of infection) to remain inside the boot due to fast evaporation of water through the slit. Hence, infection occurs at fewer sites, despite the fact that the lower one-third of the flag leaf is erect and there may be sufficient inoculum available on the surface of fully opened lamina. The above phenomenon was true for all three susceptible cultivars under study.

\section{ACKNOWLEDGMENTS}

We thank our colleagues R. P. Singh for help in statistical analysis, Mangal Singh for assistance in conduct of trials, and Yogesh Sharma and Chandrababu for their help in preparation of the manuscript. B. K. Sharma, plant pathologist, Regional Station, Dhaulakuon, extended farm facilities. This research paper is an outcome of a project DWR/RP/93-6 funded by Indian Council of Agricultural Research (ICAR), New Delhi, India.

\section{LITERATURE CITED}

1. Aujla, S. S., Grewal, A. S., Gill, K. S., and Sharma, I. 1982. Artificial creation of Karnal bunt disease of wheat. Cereal Res. Comm. 10:171-176.

2. Bains, S. S., and Dhaliwal, H. S. 1990. Production of Neovossia indica sporidia on host and non host plants. Plant Soil 126:85-89.

3. Duran, R., and Cromarty, R. 1977. Tilletia indica: A heterothallic wheat bunt fungus with multiple alleles controlling incompatibility. Phytopathology 67:812-815.

4. Mitra, M. 1935. Stinking smut (bunt) of wheat with special reference to Tilletia indica. Indian J. Agric. Sci. 5:51-74.

5. Mundkar, B. B. 1943. Studies in Indian cereal smuts. V. Mode of transmission of Karnal bunt of wheat. Indian J. Agric. Sci. 13:54-58.

6. Nagarajan, S. 1991. Epidemiology of Karnal bunt of wheat incited by Neovossia indica and an attempt to develop a disease prediction system. Technical Report, Wheat Program, CIMMYT, Mexico.

7. Nagarajan, S., Aujla, S. S., Nanda, G. S., Sharma, I., Goel, L. B., Kumar, J., and Singh, D. V. 1997. Karnal bunt (Tilletia indica) of wheat-A Review. Rev. Plant Pathol. 76:12071214.

8. Prescott, J. M. 1986. Sporidia trapping studies of Karnal bunt. Proc. Bienn. Smut Workers Workshop, 5th.

9. Singh, D. V., Srivastava, K. D., and Joshi, L. M. 1980. Occurrence and spread of Karnal bunt of wheat in India. Indian Phytopathol. 33:249-254.

10. Singh, D. V., Srivastava, K. D., and Joshi, L. M. 1985. Present status of Karnal bunt of wheat in relation to its distribution and varietal susceptibility. Indian Phytopathol. 38:507515.

11. Zadoks, J. C., Chang, T. T., and Konzak, C. F. 1974. A decimal code for the growth stages of cereals. Weed Res. 14:415-421. 